\title{
An assessment of cellulosic ethanol industry sustainability based on industry configurations
}

\author{
R.M. Cruse, C.G. Herndl, E.Y. Polush, and M.C. Shelley
}

\begin{abstract}
Thirty six billion gallons of renewable fuel is US government-mandated by 2022 , of which approximately 21 billion gallons will originate from cellulosic sources. This presents a challenge to the cellulosic biofuel industry, although it provides a window of opportunity to bring vision, policy, and science together to guide the industry's sustainable development The objective of this research was to utilize current scientific knowledge and farmers' practical experience to identify basic characteristics of the cellulosic biofuel industry that will allow it to be most functional and sustainable, such that policy might be developed, if needed, to favorably shape the industry. This study's key participants included 14 scientists actively engaged in biofuel research and 44 farmers or agriculture professionals. The methods used in this study included (1) an integrated open forum and focus group discussions with scientists and (2) a triangulation of a survey and focus group discussion with farmers. Environmental, social, technological, and logistics criteria for four conversion facility configurations were assessed. Scientists assessed multiple-feedstock-species configurations more favorably than single-species configurations for environmental metrics and high/stable feedstock production. They also assessed distributed units as having fewer logistic challenges than centralized processing units. Distributed multiple-species configurations were also assessed to have greater rural development opportunity than other configurations. In contrast, the centralized singlespecies configuration was consistently assessed as not different from, or less favorable than, the other three configurations for all of the criteria assessed. Farmers have a significant need and desire for education about the emerging cellulosic biofuel industry but anticipated environmental challenges associated with single-species conversion platforms.
\end{abstract}

Key words: cellulosic biofuels_rapid assessment—natural resources—water quality

\begin{abstract}
Renewable liquid fuel goals for the United States are based on a combination of fuels produced from starch, oil seed crops, and cellulose. The biodiesel- and starchbased ethanol industries are arguably fully developed, although there may be future market-based expansion or contractions. While this segment of our renewable liquid fuel portfolio is significant, it is overshadowed by the expected ethanol contribution from cellulosic sources (CAST 2007; Perlack et al. 2005). Thirty six billion gallons of renewable fuel is currently mandated by 2022 (Energy and Natural Resources Committee 2007), of which approximately 21 billion gallons will originate from cellulosic sources, assuming suitably rapid development of this technology occurs. The Energy Independence and
\end{abstract}

rural infrastructure, and farmers (Cruse and Herndl 2009; Yacobucci and Schnepf 2007). The current challenge involves identifying the industrial structure that most favorably impacts human and natural resources while also giving investors and farmers acceptable economic return.

The United States Department of Energy, the United States Department of Agriculture, individual states, and multiple private companies are investing heavily to develop a commercially viable cellulosicbased fuel industry (Mattingly et al. 2008; Bank Information Center 2008). This fast-track development has concentrated research resources on developing feedstock conversion technologies with relatively less emphasis on the feedstock production and logistics components of the cellulosic ethanol supply chain. Past research in adaptive ecosystem management suggests that rapid, unguided development and adoption of new technologies that maximize one variable or output of a system reduces system resilience and may result in unintended and undesirable outcomes including eventual collapse of the system (Gunderson et al.1995; Holling 1973). Similarly, life-cycle analysis holds that calculating the impact of a technology or product, here cellulosic ethanol, on the environment must include all stages of a product's life because they are interdependent (Scientific Applications International Corporation 2006). Both of these approaches suggest that evaluating potential configurations of the cellulosic ethanol industry must integrate a range of technical, economic, social, and ecological criteria.

The rapid pace of biofuel industry development precludes, in many situations, rigorous scientific evaluation and analysis of robust data related to sustainable development, especially as it relates to long term ecological consequences (Collins and Evans 2002; Jasanoff 1987). This makes it particularly

Richard $M$. Cruse is a professor of agronomy at lowa State University and director of the lowa Water Center, Ames, lowa. Carl G. Herndl is the director of graduate programs in rhetoric and composition, Department of English, University of South Florida, Tampa, Florida. Elena Y. Polush is an assistant professor in the Department of Educational Studies, Ball State University, Muncie, Indiana. Mack C. Shelley is a professor in the Departments of Statistics and Political Science at lowa State University, Ames, lowa. 
difficult for policy makers to develop rules or procedures to guide decisions favorably impacting industry sustainability. The objective of this research was to utilize current scientific knowledge and farmers' practical experience to identify basic characteristics of the cellulosic biofuel industry that will allow it to be most functional and sustainable, such that policy might be developed, if needed, to favorably shape the industry.

\section{Materials and Methods}

This study was conceived as a "rapid assessment" project. Rapid assessment projects draw on distributed expertise to gather the best existing knowledge about an emerging issue when decisions need to be made before scientific consensus is reached (Howarth et al. 2009). Further, key stakeholders' perspectives on emerging issues have been used in a variety of settings to guide decisions of importance (Government Accountability Office 2008; Goodman 2007; Martin et al. 2005). This study's key stakeholders included scientists and farmers. The methods used in this study included (1) an integrated open forum and focus group discussions (Walters 1986; Owen 1997) with scientists and (2) a triangulation of a survey and focus group discussion with farmers. Prior to initiating this project, the proposed research was reviewed and approved by the Iowa State University Institutional Review Board. A sequential mixed method design is depicted in figure 1 .

System Configuration Matrix. The workshops were guided by a system configuration matrix developed by the project team (table 1). This matrix depicts four potential configurations of the developing cellulosic biofuel industry (top) and 13 evaluation criteria, or metrics, related to technical aspects and economic, social, and environmental impacts of this industry (left side of the matrix). The four configurations listed across the top of the matrix in table 1 are a factorial combination of two different scales of feedstock conversion facilities (larger, centralized vs. smaller, distributed processing units) and feedstock conversion platforms (species-specific conversion platforms vs. flexible conversion platforms that allow multiple species to be converted to biofuel simultaneously). The distinction between centralized units and distributed processing was based on potential transportation distance of harvested, untreated biomass. Facilities that may capture biomass from distances of approximately $56 \mathrm{~km}$ (40

\section{Figure 1}

Schematic of a sequential mixed method design.

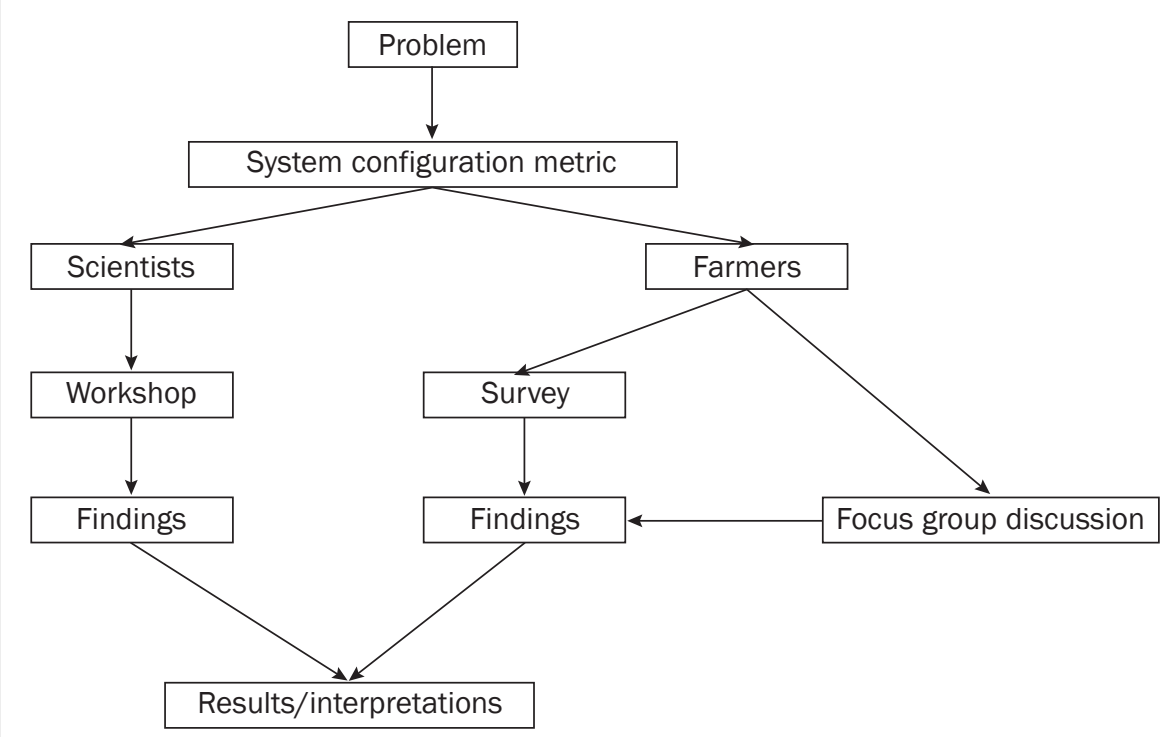

mi) or more were considered centralized. Distributed systems were defined as those that densify or totally convert the biomass to fuel within approximately $16 \mathrm{~km}(10 \mathrm{mi})$ or less of harvest. The $16 \mathrm{~km}$ (10 mi) radius used to define the distributed system was determined by the infrastructure associated with farm cooperatives or private on-farm operations. Scales between these two extremes were not considered. Species-specific platforms addressed corn (Zea mays L.) residue for this project. Within each cell formed by the junction of a given configuration (top) and metric (left side), four alternative assessments are given: red suggests major challenges will likely occur, yellow suggests caution is advised or that insufficient information is available to draw a reasonable conclusion, green indicates that the situation currently offers or will likely offer a favorable opportunity, and white signifies no opinion or that the situation is not personally applicable.

Scientist Workshop. A purposive sample of 14 scientist-experts in cellulosic biofuels were selected and invited to participate in a four-hour structured discussion workshop. Each participant was an expert on a specific metric or metrics. Disciplines included agronomy (2 representatives), soil science (2 representatives), engineering-conversion (2 representatives), sociology (2 representatives), forestry (1 representative), wildlife biology (1 representative), engineeringharvest and transportation (1 representative), engineering-feedstock storage (1 represen- tative), engineering - conversion plant design (1 representative), and economics (1 representative). Each received the matrix prior to the workshop. The purpose of the discussion was to elicit the participants' knowledge about the sustainability and functionality of the four potential industry configurations for each metric.

After a brief introduction of the research team, each metric (see table 1) was discussed individually; the discussion was led by the scientist specializing in the particular metric (two scientists for feedstock production). The lead scientist identified key issues associated with that metric as it related to each of the four industry configurations. This was then followed by a group discussion, after which the lead scientist was asked to assess the longterm functionality and sustainability of each industry configuration for that specific metric. The lead scientist was asked to assign for his or her metric a color within each cell reflecting the assessment for that metric and configuration combination. The workshop facilitator entered each discussion leader's assessment (color selection) on the research matrix, which was projected on a screen for the group to consider. All participants were then asked to evaluate the four configurations for that specific metric by similarly identifying one color within each cell for the metric under discussion on his/her own instrument. All completed instruments were collected for subsequent analysis. In addition, the forum discussion was digitally recorded 


\section{Table 1}

Configuration matrix. For each cell in the worksheet, participants were asked to mark red if a configuration suggests major challenges will likely occur, yellow if a configuration suggests caution is advised or if insufficient information is available to draw a reasonable conclusion, green if the configuration currently offers or will likely offer a favorable opportunity, and white to signify no opinion or not applicable.

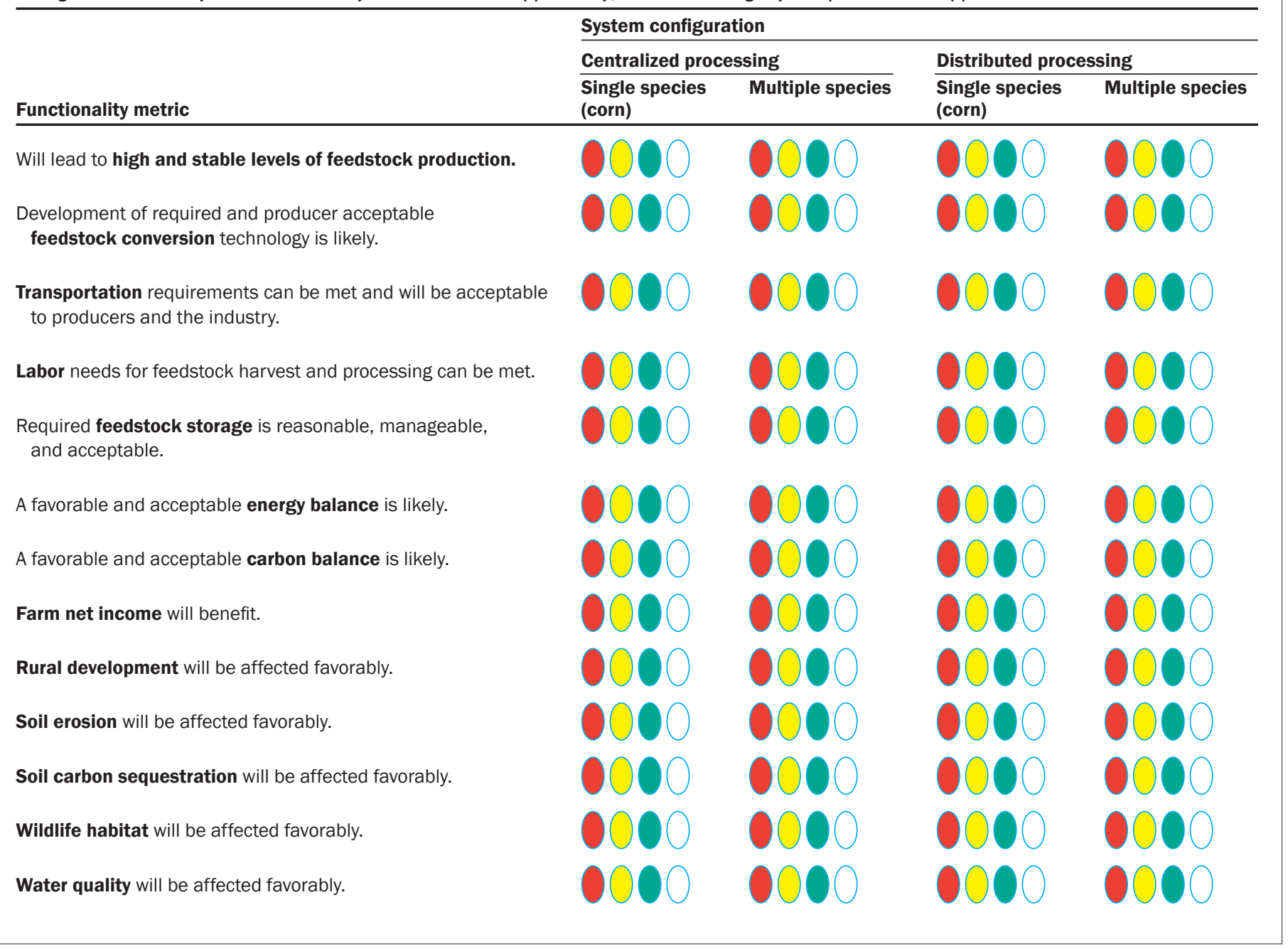

and subsequently transcribed for reference and analysis.

Farmer Survey and Focus Group. Farmers' thoughts regarding the cellulosic biofuel industry were elicited in a two-stage process: a survey of a large group and a subsequent focus group discussion with farmers from that large group. The matrix (table 1) comprised the survey instrument, and it was administered to a group of approximately 145 farmers, producers, and other agricultural practitioners that attended a 50-minute session addressing the cellulosic biofuel industry at the Integrated Crop Management (ICM) Conference at Iowa State University held on 29 November 2007. This session was based on the matrix components and led by the research team leader. After the presentation, the participants were asked to assess the sustainability/functionality of each configuration/metric combination by selecting one color within each cell of the matrix. Of the 145 participants attending this session, 44 completed and returned surveys. Furthermore, those who completed the instrument and were willing to participate in workshops devoted to discussing the components of the emerging cellulosic biofuel industry were asked to identify themselves by furnishing their contact information on the back of the instrument prior to leaving the ICM session.

Those survey participants who had indicated an interest to participate in extended discussions of the cellulosic biofuel industry were invited to a focus group meeting on the Iowa State University campus. A total of six ICM conference attendees (five farmers and a seed dealer/consultant) participated in a fourhour focus group discussion. Hereafter, this group will be referred to as "farmers." This subsample accounts for $13.6 \%$ of the original population of 44 respondents. The purpose of this focus group discussion was to gather the farmers' assessment of the potential opportunities and challenges associated with the four configurations and 13 metrics identified on the matrix. The self-selected participants were sent an agenda a week prior to the workshop so that they had time to consider the issues. The focus group discussion was organized by the matrix (table 1). The discussion proceeded from open-ended questions based on the survey response to the cellulosic biofuel presentation at the ICM conference. The matrix results of the scientists' workshop were given to the farmers during this focus group discussion. This workshop was digitally recorded and transcribed for subsequent reference and analysis. 


\section{Table 2}

Means for each metric and processing configuration combination for the scientists. For complete metric statements, see table 1. Number color coding correspond to scientists' mean assessment as it relates to challenges vs. opportunities associated with each cell.

\begin{tabular}{|c|c|c|c|c|}
\hline \multirow[b]{3}{*}{ Functionality metric } & \multicolumn{4}{|c|}{ System configuration } \\
\hline & \multicolumn{2}{|c|}{ Centralized processing } & \multicolumn{2}{|c|}{ Distributed processing } \\
\hline & $\begin{array}{l}\text { Single species } \\
\text { (corn) }\end{array}$ & Multiple species & $\begin{array}{l}\text { Single species } \\
\text { (corn) }\end{array}$ & Multiple species \\
\hline Feedstock production (12) & $1.33 a$ & $2.00 b$ & $1.42 a$ & $2.30 b$ \\
\hline Feedstock conversion (14) & 2.18 & 2.04 & 2.07 & 2.25 \\
\hline Transportation (13) & $1.58 a$ & $1.65 a$ & $2.23 b$ & $2.50 \mathrm{~b}$ \\
\hline Feedstock storage (12) & $1.38 a$ & $1.58 \mathrm{ab}$ & $1.92 \mathrm{bc}$ & \\
\hline Energy balance (13) & 2.73 & 2.92 & 2.73 & 2.85 \\
\hline Carbon balance (13) & $1.69 a$ & $2.46 \mathrm{bc}$ & $2.00 \mathrm{ab}$ & $2.73 c$ \\
\hline Farm net income (9) & 2.17 & 1.83 & 2.34 & 2.22 \\
\hline Rural development (12) & $1.83 a b$ & $2.17 \mathrm{ac}$ & $2.21 \mathrm{bc}$ & $2.67 d$ \\
\hline
\end{tabular}

Data Analysis. A mixed method approach to data collection and analysis was employed (Creswell 2009) to (1) determine the current state of knowledge about potential configurations of the emerging cellulosic ethanol industry and (2) obtain recommendations to develop an industry that is immediately functional and sustainable over the long term (Norton 2005).

The workshop transcripts were analyzed using thematic qualitative content analysis to identify key issues that presented either challenges or opportunities associated with each combination of metric and configuration. Results of this analysis are used to complement the quantitative analysis by describing the reasoning behind the participants' quantitative evaluation.

\section{Table 3}

Means for each metric and processing configuration combination for the farmers. For complete metric statements, see table 1. Number color coding correspond to farmers' mean assessment as it relates to challenges vs. opportunities associated with each cell.

\begin{tabular}{|c|c|c|c|c|}
\hline \multirow[b]{3}{*}{ Functionality metric } & \multicolumn{4}{|c|}{ System configuration } \\
\hline & \multicolumn{2}{|c|}{ Centralized processing } & \multicolumn{2}{|c|}{ Distributed processing } \\
\hline & $\begin{array}{l}\text { Single species } \\
\text { (corn) }\end{array}$ & Multiple species & $\begin{array}{l}\text { Single species } \\
\text { (corn) }\end{array}$ & Multiple species \\
\hline Feedstock production (41) & 1.90 & 2.07 & 1.85 & 1.95 \\
\hline Feedstock conversion (40) & 2.37 & 2.10 & 2.22 & 2.00 \\
\hline Transportation (42) & $1.81 a b$ & $1.54 b$ & $2.05 \mathrm{ac}$ & $1.76 a b$ \\
\hline Feedstock storage (42) & $1.55 a b$ & $1.24 a$ & $1.76 b$ & $1.55 a b$ \\
\hline Energy balance (42) & 1.81 & 1.93 & 1.88 & 2.00 \\
\hline Carbon balance (40) & 1.75 & 1.82 & & 1.85 \\
\hline Farm net income (42) & 2.07 & 2.05 & 2.21 & 2.21 \\
\hline Rural development (44) & 2.04 & 2.09 & 2.14 & 2.14 \\
\hline
\end{tabular}


Descriptive and inferential statistics were used to analyze the scientists' and the ICM participants' responses to the matrix survey configurations. To obtain numerical values for analysis from the color coding, the color red was assigned the value of 1 ; yellow, 2; and green, 3 . White votes indicating that the voters believed they did not have adequate information to judge were not included in the analysis. Using the numeric values assigned for each color code, a numeric mean value was assigned for each cell in tables 2 and 3. Within each metric (table 1), a Bonferroni multiple range test was conducted to statistically separate means between the four different configurations. A 0.05 level of confidence was used to delineate significant differences. For the scientists' data set, the number of votes $(n)$ within a given cell ranged from 9 to 14 (white votes were not considered), and for the ICM participant set, $n$ ranged from 40 to 44 .

\section{Results and Discussion}

Means and results of the Bonferroni multiple range tests are given in tables 2 (scientists) and 3 (farmers). Based on numeric analysis, mean values given in tables 2 and 3 between 1 and 1.66 are characteristic of a red vote (suggests major challenges), 1.67 to 2.33 a yellow vote (suggests caution), and 2.34 to 3 a green vote (suggests favorable opportunity). Numbers in these tables are color coded indicating to which category they belonged.

Scientists' Environmental Metrics. The scientists' assessment suggests likely cellulosic biofuel industry implications for natural resources, specifically water quality, soil erosion, soil carbon sequestration, and wildlife habitat. For all four of these environmental metrics, the centralized single-species configuration consistently had the lowest numeric values, all falling within the red range. Furthermore, mean values for singlespecies platforms were significantly different and lower than those for multiple-species platforms for all environmental metrics.

For the water quality metric, within each processing scale, single-species and multiplespecies platforms differed significantly, with multiple-species receiving the most favorable assessments. Only one assessment, multiplespecies distributed systems, fell within the green range.

For the soil erosion metric, the pattern of differences was the same as for water quality. Within each processing scale, mean values for multiple-species platforms were significantly different from, and assessed more favorably than, single-species platforms. Processing scale was not assessed differently within species platforms. Again, the only assessment that fell within the green range was that for multiple-species, distributed systems.

Three concerns about landscape systems used to produce biofuel feedstocks emerged in the discussion of the industry configurations: (1) the necessity of using land based on its production capability, (2) our uncertainty about the effects of climate change on agriculture, and (3) the effect of returning carbon-rich char to productive fields after removing corn stover. Scientists were concerned that a disproportionate share of water quality reduction and soil erosion increase will be caused by very local sites and that corn and soybeans are not the best crops for all areas of the landscape. Site-specific, precision or targeted management may be necessary to deal with water quality and soil erosion problems. There was also uncertainty about the ability and willingness of farmers to engage in precision agricultural practices. Scientists recognized the likely increase in the frequency and magnitude of precipitation events and their effect on water quality and soil erosion, especially associated with row crop monocultures. Perennials were recognized as being both good for the landscape and a potentially good biofuel feedstock Identifying where and how many of these might be planted remained a mystery. There was much discussion and uncertainty over technical issues related to soil application of char. Scientists debated the amount of carbon removed with the above-ground stover, the possible forms of char and how well it could be incorporated into the soil, and the interaction between char and soil microbes. The scientists cited the lack of definitive research on these issues as part of the uncertainty.

For the soil carbon sequestration and wildlife habitat metrics, the pattern of differences followed that for water quality and soil erosion. For both metrics, multiple-species platforms had significantly higher mean values that did the single-species platforms, but no configuration fell within the green range. Changes in processing scale did not make significant differences within species platforms. Discussions centered on historic soil carbon loss associated with annual cropping, root growth differences between annuals and perennials affecting soil carbon, and the positive impact perennials could have on this metric. The scientists agreed that returning carbon-rich biochar to the soil was potentially beneficial and that more research was needed on this potential practice.

Wildlife habitat discussions reemphasized environmental elements as emergent qualities of a system, arguing that economic pressure brought on by high commodity prices would lead to loss of buffer strips, CRP, and wetlands, leading to degradation of our soil and water and negative wildlife impacts. Analysis of the configurations was guided by the principle that states, "the more diversified the plantings, the more diversified the wildlife." The biofuel industry was viewed from multiple perspectives relative to wildlife. While corn and beans are not good wildlife habitat, a monoculture of perennial such as switchgrass (Panicum virgatum L.) is not ideal either. Multiple-species native grass crops were judged best for the wildlife habitat.

Based on environmental assessments of the four configurations, the form the cellulosic biofuel industry actually takes, and thus the impact it will have on natural resources, will be heavily influenced by the technological, logistic, and social elements of the system represented by the other nine functionality metrics in the matrix.

Scientists' Technological Metrics. For the four technological metrics-feedstock production, feedstock conversion, energy balance, and carbon balance-the scientists' evaluation resulted in significant configuration differences for feedstock production and carbon balance only. Configurations containing multiple-species conversion capabilities were expected to have more stable feedstock production and a more favorable carbon balance than single-species configurations. Production of high and stable levels of feedstock for configurations requiring a single species (corn in this study) was considered a challenge. Not only was this requirement viewed as a challenge, it rated significantly different and with seemingly more known challenges than configurations with conversion platforms accepting multiple species. Even with multiple-species configurations, however, the scientists remained uncertain that high and stable levels of feedstock production would offer a favorable opportunity - the mean response still fell within the yellow color range.

In the discussion, scientists suggested that achieving high levels of feedstock produc- 
tion was a different and possibly conflicting goal relative to stable levels of feedstock production. With this distinction in place, they argued that three factors favored multiplespecies configurations: (1) the variability of the landscape; (2) the variability of the weather, especially with climate change, and (3) the increased possibility of pathogens with the increased number of warm days due to climate change.

For carbon balance, mean values for multiple-species configurations fell in the green range and were significantly different than for single-species platforms (both in the yellow range). In discussion, scientists commented that reducing transportation distances with distributed configurations would benefit carbon balance. Similarly, a distributed system might allow carbon-rich biochars to be produced with $\mathrm{pH}$ appropriate for the local soils, enhancing carbon sequestration. Finally, scientists commented that multiple-species platforms using thermochemical processes would be "more robust" and accommodate feedstocks from lands not already in corn and soybean production.

For conversion platforms, there were no significant differences between configurations. All mean values fell in the yellow range. Responses suggested an element of uncertainty existed relative to development of an acceptable conversion platform for any of the configurations. This uncertainty seemed to be fueled by lack of convincing existing research and/or demonstration facilities. In the discussion, there was also debate over the relative merits of biochemical processes and thermochemical processes.

The scientists indicated that energy balance would be favorable for all configurations. Statistically, there was no difference between configurations, and mean values were all in the green range. Scientific evidence is sufficiently solid to suggest cellulosic conversion of feedstocks will produce substantially more energy than that used to grow and convert the materials into fuels. Some uncertainty existed in the tradeoff between the economies of scale captured with centralized processing and the movement of feedstock to the processing plant and the distribution of co-products such as biochar back to the farm fields.

Scientists' Logistics Metrics. Significant assessment differences existed for scale with transportation and feedstock storage. Transportation of feedstock with low energy density has been, and will likely remain, an issue attracting attention. Centralized processing seems to present a major transportation challenge, with mean values for both single-species (1.58) and multiple-species (1.65) platforms falling within the red range. Distributed systems (single-species: 2.23, yellow; multiple-species: 2.50 , green) were assessed significantly higher than their centralized counterpart. Distributed systems accepting multiple species seemed to present fewer challenges, with a mean value of 2.50 . The concern for logistics in the field involved the time lost in harvesting corn stover after corn grain was harvested, the number of passes through the field required to harvest both grain and stover, and the high seasonal labor demands imposed by single-species feedstocks. Scientists expressed a concern that these potential problems would prevent many farmers from participating in cellulosic feedstock production. The group suggested the need for developing single-pass harvesting technology that could accommodate both corn grain and corn stover. The logistical challenges associated with transporting low-density material suggested the need to develop densification technology that could operate close to the source of feedstock. The scientists suggested pelletization to increase energy density and reduce transportation costs, making cellulosic fuels more competitive with corn grain ethanol. Scientists also expressed concern that the distribution network for cellulosic feedstock was as yet undeveloped and uncertain and that concentrating transportation in a single location as with centralized processing would cause congestion, road damage, and a demand for more rolling stock. As one scientist summarized the discussion, "any time we can move the processing closer to the collection point is going to significantly improve the issues we have with transportation."

Similar to transportation, storage of the low energy density and bulky materials are projected to pose significant challenges, especially for centralized facilities. The mean values for centralized processing fell within the red range. There was no significant difference between the centralized single-species configuration and distributed single-species configuration. In their discussion scientists expressed concern about (1) the size of storage required for low density material, (2) the dangers of fire at centralized sites, (3) the need to transport feedstock internally within large, centralized storage facilities, and (4) the uncertainty of the effects of long storage on densified bio-oils. The storage expert summarized the discussion by stating that "spreading the harvest season over a period of time is an advantage." And this advantage could be achieved with multiple-species feedstocks that come to senescence at different times of the year.

For the labor metric, all mean values fell within the yellow range without significant differences between configurations. This suggests that scientists did not anticipate major challenges in meeting the labor needs of the cellulosic industry, although sufficient uncertainty remains.

Scientists' Social Metrics. Rural development encompasses the integrated effect of this new industry. It considers impacts on infrastructure, quality of life, economics, and environment. There was no significant difference in mean values among the centralized single-species, centralized multiple-species and distributed single-species configurations. However, the distributed multiple-species configuration was significantly different and viewed as more favorable to rural development than the other configurations. In fact, this configuration mean was in the green range, suggesting a positive opportunity, while the others were in the yellow. The discussion suggested four issues would influence rural development: (1) the local competition between the "consumption of amenities [which] runs up against the production of commodities" where energy production competes with ecological and recreational values; (2) whether the processing plants were owned locally or by outside investors and where the money in the system goes; (3) how the externalities of the production process are internalized by the local community; and (4) whether or not there are multiple value-added products produced by the system. Expected farm net income means fell within or very close to the yellow range for all configurations and were not significantly different between configurations. Scientists assumed that farmers will "choose the system that is best for them rather than us choosing the system that will give them the highest income." Furthermore, much uncertainty remains regarding costs of producing, harvesting, storing, and transporting feedstocks compared to prices the cellulosic fuel industry can or will pay for these materials. Finally, scientists recognized that farm 
net income is always affected by government policy, and the consensus of the group was that we "aren't going to stay in the current policy scenario."

Farmers' Assessment. The scientists' evaluation of the potential industry configurations can be supplemented by the practical and local knowledge of farmers who will supply the feedstock and live in the rural communities where biofuels are produced. The ICM participant assessment of the potential industry configurations had statistically significant differences for only 3 of the 13 metrics: water quality, transportation, and storage. For the remaining 10 metrics, the ICM participant evaluation fell in the yellow and red ranges. Thus, for some metrics where scientists made significant distinctions between configurations, the ICM participants did not. On others, notably transportation and storage, the ICM participants made different distinctions than did the scientists.

Farmers' Environmental Metrics. For the water quality metric, multiple-species configurations had significantly higher mean values than single-species configurations. As with scientists, it is platform rather than scale that distinguishes between configurations. Within either the single-species or multiplespecies platforms, mean values for different scales were not significantly different. For the remaining 3 environmental metricssoil erosion, soil carbon sequestration, and wildlife habitat-there were no significant differences in mean values between configurations. Importantly, however, 10 of the 16 cells in the four environmental metrics fell within the red range. The other 6 fell in the yellow range. This suggests ICM participants anticipate potential environmental challenges associated with the industry.

During the focus group discussion, farmers expressed concerns about the effects of the cellulosic biofuel industry on both water quality and water quantity. Farmers discussed the prediction that corn yields would soon reach $18.8 \mathrm{t} \mathrm{ha}^{-1}$ (300 bu ac${ }^{-1}$ ) and that this increased production would require them to increase fertilizer application rates. With an increased use of fertilizer, farmers recognized an increased risk of leaching and surface losses of nutrients to water bodies. It is likely that this concern accounts for the significant difference between the singlespecies and multiple-species platforms for the water quality metric. Some farmers suggested that this situation would require more education for farmers. One farmer suggested that small wetlands located at the bottom of fields could become "in-house biofilters" to protect water quality. Farmers also expressed a concern that as more land is put into corn production for the cellulosic industry and as more processing plants are built, there will be increased competition for water.

During the focus group, farmers discussed soil erosion in combination with the reduction of soil organic matter and frequently used the general term "soil health." The group agreed that the threat to soil health was major. For the single-species platform, the means for soil erosion fell in the red range for both scales. Farmers were concerned that removal of residue would create a "chance for a lot more soil erosion but [also] deterioration of the organic matter contents of the soil and just the declining health of soil.'They stated that increased corn production would bring CRP lands back into production and that farmers would plow up buffer strips by plowing as close to the fences as possible. The discussion group also suggested that demand for corn stover could lead to "mining" the land, especially if land was owned by out of state investors or family members living in other states. The means for multiple-species platforms, however, were not significantly different. Farmers said very little about multiple species and soil health other than that they did not know enough about harvesting and managing perennials such as switchgrass

In their environmental metrics discussion, the farmers repeatedly expressed their uncertainty about the future of the cellulosic industry and commented that they did not have adequate knowledge of specific issues to make careful judgments. Farmers commented on the complexity of the emerging industry, saying that it was "a lot to bite off and chew on." They also acknowledged the fast pace of change in prices and technology, specifically that because the "pace changes so fast," it is difficult to deal with "the realistic things."

Farmers' Logistics Metrics. Transporting and then storing multiple species in centralized processing configurations seemed the biggest concern for farmers. For both transportation and storage, the centralized multiple-species configuration was significantly different and lower than for the distributed single-species configurations. The farmers' evaluation differed from that of the scientists who had the highest mean values for the distributed multiple-species configu- ration (transportation: 2.50, green; storage: 2.17, yellow). Farmers had many questions about the costs of transporting corn stover to centralized and distributed plants and about the technology for preprocessing feedstock at or near the farm. Farmers said that preprocessing corn stover at the local co-op was an efficient use of existing infrastructure. In general, farmers were more comfortable with transporting and storing corn residue than other products because they are familiar with corn and unfamiliar with perennials such as switchgrass.

The lack of knowledge and inability to evaluate alternatives was a common theme throughout the farmers' discussion in the focus group. They expressed uncertainty about the future of the cellulosic ethanol industry. Farmers were uncertain about what feedstocks the industry would want and in what form that feedstock should be. They questioned the impact to the cellulosic biofuel industry when the cost of crude oil changes. In discussing specific metrics, farmers repeatedly said, "I don't know." One farmer summarized a discussion of the policy implications of cellulosic ethanol by stating, "I think there is so much unknown about this that we need; there does need to be more education on this."

In discussing their general response to the matrix, the farmers suggested that the lack of distinctions between configurations in the farmers' assessment (table 2) might be due to the group's lack of information about and uncertainty surrounding the development of the cellulosic biofuel industry. Multiple farmer comments alluded to lack of knowledge regarding this industry and the desire to learn more.

Need for Policy and Education. Without influences such as policy, new technology, and innovation, the cellulosic biofuel industry will most likely develop following economies of scale (Richard 2010; Wright and Brown 2007). Because this industry will have broad social and economic impacts, unguided development following economies of scale (centralized configurations) could result in a variety of challenges best avoided, or at least recognized and addressed. Based on scientists' opinion, it seems that a cellulosic biofuel industry that is centralized and relies on a single type of feedstock could present more challenges than other industry configurations. In general, scientists believed that distributed and multiple-species config- 
urations favored those metrics often related to sustainability. For logistics issues (i.e., storage and especially transportation), scale was the strongest deciding factor-distributed systems offered fewer concerns, particularly for multispecies conversion technologies. Scientists repeatedly cautioned, however, that implications of climate change should be factored into the evaluation of potential industry configurations.

In general, farmer knowledge about the cellulosic biofuel industry was limited, and this seems to have led to their lack of clear assessment distinctions between potential industry configurations. However, like the scientists' evaluation, the farmers' evaluation of the configurations suggested that multiple-species platforms offered fewer challenges to water quality than single-species platforms. Selected farmers expressed multiple other concerns. However, patterns regarding the likely performance of platform type or scale were not sufficiently consistent to draw conclusions regarding which configuration this farmer group thought offered fewest challenges. This group had multiple well-founded questions about the cellulosic biofuel industry and stated on a variety of occasions that they needed more information/education about both the technology and crops other than corn if they were to make reasoned arguments with confidence.

Both groups concurred that (1) the emerging system is very dynamic and (2) how it develops remains uncertain, but policy will have a definite impact on its structure.

\section{Summary and Conclusions}

Scientists associated with the cellulosic biofuel industry believed multiple-species configurations would be more favorable than single-species configurations for environmental metrics and high/stable feedstock production. They also assessed distributed configurations as having fewer logistic challenges than centralized processing units. Distributed multiple-species configurations were also assessed to have greater rural development opportunity than other configurations. In contrast, the centralized single-species configuration was consistently assessed as not different from, or less favorable than, the other three configurations for all of the 13 metrics assessed. Farmers have a significant need and desire for education about the emerging cellulosic biofuel industry but anticipated environmental challenges associated with single-species conversion platforms.

It is clear that alternative configurations of the emerging cellulosic biofuel industry will impact natural resources differently. A favorable outcome will likely depend on policy guidance, and in the absence of favorable policy, risks to multiple natural resources will be substantially increased, especially if centralized processing facilities dominate and processing is limited to a single cellulosic plant species.

\section{References}

Bank Information Center. 2008. Biofuels, Agrofuels, the International Financial Institutions and Private Investment: A General Panorama. Washington, DC: Bank Information Center. http://www.bicusa.org/en/ Article.10385.aspx.

Collins, H.R., and R. Evans. 2002. The third wave of science studies: Studies in expertise and experience. Social Study of Science 32(2):235-96.

Council for Agricultural Science and Technology (CAST). 2007. Convergence of Agriculture and Energy: II. Producing Cellulosic Biomass for Biofuels. CAST Commentary QTA2007-2. Ames, IA: Council for Agricultural Science and Technology.

Cresswell, J.W. 2009. Research Design: Qualitative, Quantitative, and Mixed Methods Approaches, 3rd Ed. Thousand Oaks, CA: Sage.

Cruse, R.M. and C.G. Herndl. 2009. Balancing corn stover harvest for biofuels with soil and water conservation. Journal of Soil and Water Conservation 64(4):286-291, doi:10.2489/jswc.64.4.286.

Energy and Natural Resources Committee. 2007. Energy Independence and Security Act of 2007. Washington, DC: US Senate, Energy and Natural Resources Committee. http://www.gpo.gov/fdsys/pkg/BILLS110hr6enr/pdf/BILLS-110hr6enr.pdf.

Goodman, S. 2007. National Security and the Threat of Climate Change. Alexandria, VA: CNA's Institute for Public Research

Government Accountability Office. 2008. Expert Opinion on the Economics of Policy Options to Address Climate Change. A Report to Congress Requesters. GAO-08605.Washington, DC: Government Accountability Office.

Gunderson, L.H., C.S. Holling, and S.A. Light. 1995. Barriers and Bridges to Renewal of Ecosystems and Institutions. New York: Columbia University Press.

Holling, C.S. 1973. Resilience and stability of ecological systems. Annual Review of Ecological Systems 4:1-23.

Howarth, R.W., S. Bringezu, M. Bekunda, C. de Fraiture, L. Maene, L. Martinelli, O. Sala. 2009. Rapid assessment on biofuels and environment: Overview and key findings. 1-13. Howarth and S. Bringezu (eds.), Biofuels: Environmental Consequences and Interactions with Changing Land Use. Proceedings of the Scientific
Committee on Problems of the Environment (SCOPE) International Biofuels Project Rapid Assessment, Gummersbach Germany, September 22-25, 2008. Ithaca, NY: Cornell University. http://cip.cornell.edu/biofuels/. Jasanoff, S. 1987. Contested boundaries in policy-relevant science. Social Studies of Science 17:195-230.

Martin, T.G., P.M. Kuhnert, K. Mengersen, and H.P. Possingham. 2005. The power of epert opinion in ecological models using Bayesian methods: Impact of grazing on birds. Ecological Applications 15(1):266-280.

Mattingly, J., F. Robb, and J. Wong. 2008. Life cycle analysis: Principles and practice. In Cellulosic Biofuels, ed. C. Werner. Environmental and Energy Study Institute. Washington, DC: National Risk Management Research Laboratory. http://www.epa.gov/nrmrl/lcaccess/pdfs/ chapter1_frontmatter_lca101.pdf.

Norton, B. 2005. Sustainability: A Philosophy of Adaptive Ecosystem Management. Chicago: University of Chicago Press.

Owen, H. 1997. Open Space Technology: A User's Guide, 2nd ed. San Francisco, CA: Berrett-Koehler Publishers.

Perlack, R.D., L.L. Wright, A.F. Turnhollow, R.L. Graham, B.J. Stokes, and D.C. Erbach. 2005. Biomass as feedstock for a bioenergy and bioproducts industry: The technical feasibility of a billion-ton annual supply. Publication DOE/GO-102995-2135/ORNL TM-2005/66. Oak Ridge, TN: Oak Ridge National Laboratory. http:// feedstockreview.ornl.gov/pdf/billion_ton_vision.pdf.

Richard, T.L. 2010. Challenges in scaling up biofuels infrastructure. Science 329(5993):793-796.

Scientific Applications International Corporation. 2006. Life cycle assessment: principals and practice. EPA/600/ R-06/060. McLean, VA: Scientific Applications International Corporation. http://www.epa.gov/ord/ NRMRL/lcaccess/pdfs/600r06060.pdf.

Sissine, F. 2007. Energy Independence and Security Act: Major Provisions. Congressional Research Service Report for Congress. Order Code RL34294.

Walters, C. 1986. Adaptive Management of Renewable Resources. New York: McMillan.

Wright, M., and R.C. Brown. 2007. Establishing the optimal sizes for different kinds of biorefineries. Biofuels, Bioproducts, and Biorefining 1(3):191-200.

Yacobucci, B.D., and R.Schnepf. 2007. Ethanol and Biofuels: Agriculture, Infrastructure and Market Constraints Related to Expanded Production. Congressional Research Service Report to Congress. Order Code RL33928. 